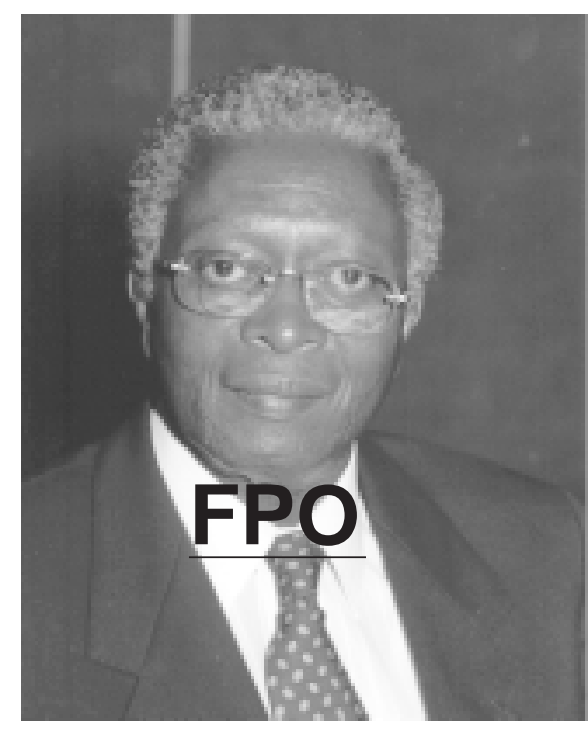

Professor D. A. Bekoe

congruent with the goals of IUPAC. He noted the special problems caused in Africa by population growth. In regard to food production, for example, new lands are brought into cultivation only after the old lands have been exhausted. Prof. Bekoe added that research funding in some countries is weak and getting weaker, having in some cases been reduced by two-thirds. Even so, AAPAC is developing opportunities for joint efforts to obtain support by giving chemical researchers a voice with governments.

Prof. Bekoe suggested that AAPAC can help promote teaching and learning in ways unique to Africa. The solutions sought should be Africa-relevant because learning strategies and cost-effective solutions are not necessarily the same in all parts of the world. Through the International Chemistry Conference in Africa (ICCA) series, AAPAC has already established a dialogue on chemical education. AAPAC discussions on environmental chemistry, theoretical chemistry, and natural products chemistry are stimulating young researchers. Now those new scientists will need access to faster, modern methods of obtaining and analyzing data.

Prof. Bekoe noted that AAPAC and IUPAC both have long-term objectives to foster chemical research and the application of chemistry and allied sciences, with special emphasis on capacity building. Therefore, he said, it is necessary that there be liaison between the two organizations with the goals of (1) strengthening of national chemical associations in the region, (2) working together to encourage chemistry-related industry, particularly large industry, to contribute to sustainable development, creation of wealth, and improvement of the quality of life in Africa, (3) finding ways to work with and learn from IUPAC and other bodies such as ICSU, COSTED, UNIDO and UNESCO, (4) improving the resource base of AAPAC, and (5) developing more effective scientific communications in the region.

\section{Status of Chemistry on the African Continent}

Only two countries in Africa-Egypt and South Africa-are members of IUPAC. There is clearly a need to increase African participation. Prof. Jortner, quoting from an excellent report written for IUPAC by Dr. C. F. Garbers, noted that while Africa includes $62 \%$ of the world's developing countries, the distribution of development is not homogeneous. Some 29 of the 51 countries published less than 10 abstracted journal articles in 1996, while Egypt published 2560 in the same year. Among the 45 countries in sub-Saharan Africa, only 3 countries produced the great majority of published research articles in chemistry. They were South Africa (1359 abstracts), Nigeria (384 abstracts), and Kenya (97 abstracts). No abstracts were cited from 5 countries and another 21 countries produced less than 10 abstracts each. Rising university enrollments (mostly in the Arts) and stagnant budgets have caused average per-student expenditures to fall from $\$ 6,300$ in 1970 to $\$ 1,500$ by 1988 .

Dr. Garbers recommended that if IUPAC wishes to embark on further initiatives, a detailed study should be made of an area which is served by so many agencies. He noted that the Committee on Teaching of Chemistry has new and important initiatives to contribute. He suggested that IUPAC, being active in all fields of chemistry and with extensive expertise in publication, could become involved in the preparation of texts for training and reference in selected fields of importance in developing countries. These might include water quality, human health, food analysis, and access to chemical information. Also, the work of CHEMRAWN should be extended to techno-economic analysis of countries and regions to identify potential industrial and market initiatives.

Dr. Garbers noted further that, while neither IUPAC or UNESCO is a major funding organization, together they have the ability to provide direction-giving inputs. One possible approach is outlined in the recommendations made by the recent report of the IUPAC Task Team of African Chemists convened in 1997. The Task Team recommended that IUPAC/UNESCO coordinate a Pan-African chemistry development project, implementing recommendations that will come from a series of five regional workshops. The workshops will involve all African countries, which will be invited to assess the types of support and other inputs necessary. Major funding will be sought from local governments and national and international development agencies.

Dr. Garbers emphasized that there is a tendency to 
generalize about Africa, yet huge differences exist among countries and institutions. Many uncertainties and deficiencies exist in higher education, which remains elitist and selective in the admission of students. The rising demand for access to higher education is prompting reconsideration of the university's role in Africa. However,

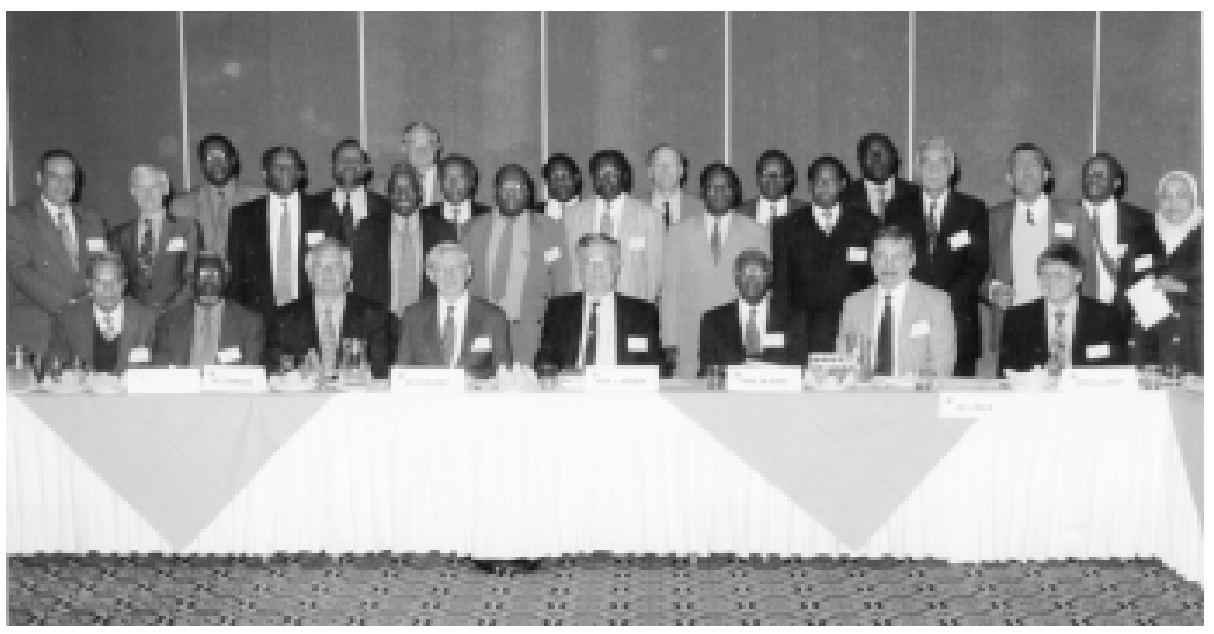
the outcome may ultimately be dependent on political decisions by local governments.

\section{Status of Chemical Education in Africa}

The African university environment has changed since the 1960s, a decade described by Dr. B. M. Abegaz as one of hope, euphoria, and romanticism. By the 1970s, expectations had been somewhat reduced, stung by a wave of military coups and the growing politicization of higher education. In the 1980s, disillusionment and decline were the norm. Overcrowding in the universities led to a growing pessimism among students and faculty, along with an overall decrease in quality. The 1990s have seen new hope for successful change and transformation of higher education. However, this is accompanied by increased "donor fatigue" among external agencies and nations.

Prof. John Bradley, Chair of IUPAC's Committee on the Teaching of Chemistry, provided a statistical overview of education of Africa. He noted that the population of Africa was 778 million in 1998 and will grow to 930 million by the year 2005. 236 million (36\%) of the current African population are of primary and secondary school age (6-17 years). Prof. Bradley added that the adult illiteracy rate in Africa is $40 \%$, due partly to the fact that public expenditures for education are very low on average, about $6 \%$ of the GNP. Nevertheless, numbers of students have increased substantially since 1980 with enrollment ratios in tertiary education currently at $6 \%$, in secondary education $32 \%$, and in primary education $72 \%$. In natural sciences and engineering, the percent of enrolled students varies according to country between $11 \%$ and $34 \%$. The number of science students per 10,000 inhabitants is approximately one-tenth that found in Latin America and one-fiftieth that of the United States.

Prof. Bradley observed that many African university professors must undertake supplementary nonaca-

demic jobs to augment meager incomes. There is a chronic shortage of textbooks, virtually all of which must be imported from outside the continent. Laboratories are often cancelled because of a shortage of reagents.

Prof. E. M. R. Kiremire reported on the dire situation facing higher education in Zambia, typical of African countries. Tremendous inflation, exacerbated by a lack of government support and political instability, have caused serious problems. Prof. Kiremire noted that 300 lecturers left Zambia during the 1980s and, unfortunately, for every two professors lost, only one professor was recruited. The age profile of the scientists remaining behind is not encouraging. Some $40 \%$ of the university staff are over 50 years of age.

Prof. Kiremire urged that the educational system must concentrate on student study skills and motivation, conditions of service for teachers, improvement of teaching aids, and infrastructure. There is a great need for information technology and library development. Journals published since 1975 are lacking in Zambia, as are textbooks and, especially, computers. There is a need to strengthen basic research and development in Africa to help provide relevance for chemical education. Basic political support with no strings attached needs to be developed for chemical research and education.

Prof. T. T. Mokoena of Botswana reminded the participants that one of the greatest challenges to chemical education in Africa is to make chemistry understandable to the poor. It is extremely important, he said, that the educational system have a clear understanding of the educational environment from which students come and a plan for where the graduates will go.

Prof. Mokoena suggested that undergraduate chemistry programs in Africa suffer from a lack of goals and objectives, overcrowded and authoritarian undergraduate curricula, general scarcity of modern resources, "tunnel vision" caused by undue emphasis 